\title{
CONCEPÇÕES DE MONTAGEM EM SOKÚROV: A SÍNTESE COM DUAS VERTENTES DO CINEMA RUSSO.
}

\author{
Marcos Kathalian ${ }^{1}$
}

\begin{abstract}
Resumo: Este artigo analisa as teorias e concepções de montagem cinematográfica de Serguei Eisenstein e Andrei Tarkóvski e seus pontos de contato com a prática de montagem do realizador russo Aleksandr Sokúrov (1953-). Esta análise tem como objeto central de investigação o filme documentário Hubert Robert, uma vida afortunada (Rússia, 26', Cor, 1996). A análise dos procedimentos de montagem de Sokúrov é discutida à luz do conflito latente entre duas concepções teórico-práticas dos escritos de Tarkóvski e Eisenstein. No artigo procuro demonstrar como Sukúrov, neste filme, utiliza-se de procedimentos cruzados entre essas duas concepções, e a partir dos escritos sobre cinema dos formalistas russos, procuro sugerir que Sokúrov opera uma nova síntese com sua montagem, assemelhando-se àquilo que Boris Eikhenbaum propôs com o termo de discurso interior.
\end{abstract}

Palavras chave: Sokúrov; Teorias de Montagem; Cinema Russo;

\begin{abstract}
This article examines the theories and concepts on film from Sergei Eisenstein and Andrei Tarkóvski and their points of contact with the editing practice of the Russian film director Aleksandr Sokurov (1953-).The analysis of Sokurov's editing procedures is done taking the documentary film Hubert Robert, a Fortunate Life (Russia, 26', color, 1996) as a central case study. The Sokurov work is discussed in in thelight ofthe latent conflict between conceptions of theoretical andpractical writings of Eisenstein and Tarkóvski. In the article I demonstrate how Sokúrov makes use of procedures both from Eisenstein and Tarkóvski, and from the writings on cinema of the Russian formalists. I try to suggest that Sokúrov operates a new synthesis with their editing conceptions, resembling what Boris Eikhenbam proposed with the term inner speech.
\end{abstract}

Key Words: Sokúrov; Editing Theories; Russian Cinema;

\section{Introdução}

Meu objetivo neste artigo é propor uma teoria interpretativa para os procedimentos de montagem em Aleksandr Sokúrov, a partir da contraposição produtiva de duas vertentes bastante marcadas nas teorias de montagem com base na cinematografia soviética e russa: as teorias de montagem de Sergei Eisenstein e as concepções de Andrei Tárkóvski.

No artigo procurarei mostrar como estas duas concepções - tomadas aqui para efeitos demonstrativos como polos de oposição sobre a montagem no cinema - são reavaliadas por Sokúrov e reincorporadas em sua prática. Irei propor que, eventualmente, a obra de Sokúrov gera uma nova síntese que não opta por nenhuma dessas concepções anteriores, mas parece flutuar entre elas, assumindo um comentário crítico de caráter auto reflexivo. Esta prática de

\footnotetext{
${ }^{1}$ Doutorando em Comunicação e Linguagens pela UTP. Email: marcosk@ brain.srv.br
} 
reflexividade, na avaliação que proponho, operaria segundo uma figura de linguagem que pode se assemelhar à figura do monólogo interior do espectador, tal qual formulado originalmente pelo formalista russo Boris Eikhenbaun, no contexto dos estudos formalistas russos sobre cinema.

Estas discussões ocorrerão a partir da análise específica de um filme, que parece ser notável como ilustração desse novo sentido da montagem: o filme Hubert Robert, uma vida feliz, documentário de 1996, de 26 minutos, sobre a vida do pintor francês do século XVIII.

Para realizar este percurso, iniciarei primeiro por uma recapitulação e discussão das concepções de montagem de Eisenstein e Tarkóvski; depois procurarei mostrar como estas concepções podem ser encontradas no filme objeto desse estudo, ao qual descreverei essencialmente em seus aspectos plásticos e de montagem; e finalmente, na terceira parte deste artigo, irei apresentar a concepção de Eikhenbaum sobre o monólogo interior e propor se esta visada não poderia ser uma boa chave interpretativa da síntese de montagem que, creio, Sokúrov procura realizar.

\section{A montagem e o plano segundo Eisenstein e Tarkóvski}

Começo, portanto, pela montagem de atrações e intelectual de Eisenstein. Como é conhecido, a originalidade de Eisenstein deveu-se, além da obra cinematográfica referencial, aos numerosos trabalhos teóricos sobre praticamente todos os aspectos do cinema. Sua reflexão sobre montagem, conforme François Albera (2002) notou, passa por diversos percursos: de simples montagem de atrações, onde surge a ideia da montagem como choque, como duas oposições, tese, antítese, gerando uma imagem conceito síntese (XAVIER, 2008) - ideias desenvolvidas a partir da experiência teatral revolucionária com a convivência com as ideias de Meyerhold e dos teóricos construtivistas e formalistas russos (ALBERA, 1998) - até as ideias mais sofisticadas de montagem intelectual e montagem dentro do plano (EINSENSTEIN, O sentido do filme, 2002:105-145).

No primeiro exemplo de montagem como choque, como conflito de duas atrações dispostas para provocar uma reação no espectador, reação esta proporcionada pela oposição de duas imagens - pode-se citar o famoso exemplo de A Greve (1924). Neste filme, o massacre dos operários é intercalado pela justaposição de cenas de um abatedouro de bois, onde a operação comparativa promove a ideia de assassinato em massa, brutal, covarde e inexorável. Como segundo exemplo, a de montagem intelectual e depois de montagem dentro 
do próprio plano, costuma-se citar quase todas as sequências de Outubro (1927); mas especialmente as sequências de Kerenski subindo as escadas do palácio de inverno, sua associação com Napoleão e uma ave de rapina. E como montagem dentro do próprio plano, a figura de frente em oposição à própria figura de fundo, um bom exemplo, amplamente demonstrado por Eisenstein, pode ser encontrado nas duas partes de Ivan o Terrível (1945) e conforme se pode observar também nos escritos específicos sobre esse filme, seja no roteiro escrito e postumamente publicado, como nos diversos textos teóricos posteriormente compilados por Jay Leyda.

Neste percurso, as teorias de montagem em Eisenstein recebem influxos novos. Seja pela assunção mesma das próprias inovações da forma cinema, como foi o caso de suas reflexões sobre o som e depois sobre a cor no cinema (EISENSTEIN, O sentido do filme, 2002: 51-77), ou seja, pela análise erudita que o cineasta fazia de numerosas referências artísticas em quase todos os campos das artes e também das ciências humanas - como foi o caso da noção de pensamento selvagem contida nos escritos de Levy Bruhl; mas, sobretudo também a partir dos exemplos advindos da arte oriental (caligrafia, pintura, teatro Nô e Kabuki) (IDEM, 2002:29-43) - o que sempre distinguiu a concepção de a montagem de Eisenstein é a ideia básica e central de conflito, de oposição, a montagem como operação não naturalista e teleológica, não como o ponto de vista de um observador privilegiado como Pudovkin descreveria em 1926 no seu Film Technique (XAVIER, 2008).

O conflito em Eisenstein é a base não apenas da montagem, mas da própria arte e pode ser observado entre planos:

O que, então, caracteriza a montagem e, consequentemente, sua célula - o plano? A colisão. O conflito de duas peças em oposição entre si. O conflito. A colisão. Tal como a base de qualquer arte é o conflito (uma transformação imagística do princípio dialético). (EISENSTEIN, A forma do filme, 2002:42-43).

Eisenstein em toda sua obra vai aprofundar essa noção de conflito: conflito de direções gráficas, de escalas, de volumes, de massas e no seu texto talvez de maior dedicação à montagem, justamente intitulado "métodos de montagem", o realizador soviético irá avaliar criticamente cinco tipos de montagem: montagem métrica, montagem rítmica, montagem tonal, montagem atonal e finalmente montagem intelectual, todas tendo como princípio estruturador a série de conflitos dentro ou fora do quadro ou a partir de ideias estruturantes (EISENSTEIN, A forma do filme , 2002:79-88).

Com propriedade Albera (2002) nota que no fundo desta concepção de montagem de Eisenstein havia um substrato de base formalista e de estranhamento - reconhece-se aqui a 
noção de Ostranenie (estranhamento), tão importante dentro do contexto de uma arte não realista.

É Eisenstein mesmo que vai propor no seu texto referencial sobre uma natureza não indiferente, a visão de que a arte é uma opção de tornar o natural, não natural, isto é, desnaturalizar a natureza, para torná-la arte, para produzir um conceito, que seria a forma suprema da verdade artística (EISENSTEIN, La non indifférente nature/2, 1978).

Assim, se já em seu primeiro experimento cinematográfico, O Diário de Glumov, inserido como "atração" em uma peça que dirigiu e depois em A Greve e Encouraçado Potemkin, a montagem atua como oposições seca, fortemente destinadas a provocar - pelo corte -sínteses conceituais entre as imagens anteriores, provocando uma espécie de imagemconceito não contida nas anteriores. Esses efeitos de imagem conceito gerada como síntese das imagens anteriores podem ser observados no filme Outubro. Uma montagem que ganhará cada vez mais recursos audiovisuais, a partir das experiências sonoras com Alexandre Nevski e, sobretudo, com a cor em Ivã o Terrível. Neste momento final da obra do cineasta a montagem será talvez menos didática, menos indicativa de uma leitura unívoca e será mais matizada, com maiores espectros de significação e jogando com as sincronias e assincronias entre o som, o ritmo plástico interno, a cor, a disposição dos personagens na mise em scene, a atuação e assim por diante.

A análise habitual procura identificar uma espécie, portanto de segunda fase em Eisenstein e procura fazer uma análise política dessa guinada do diretor soviético que, após um encantamento inicial com a revolução, teria seu trabalho cada vez mais cerceado e sujeito as imposições implícitas ou explicitas da censura (SKLÓVSKI, 1973: 172-175; XAVIER 2008: 176-177).

Cabe aqui notar que se a explicação a posteriori desta inflexão da montagem em Eisenstein pode ser talvez confortável e dignificante como uma história bem contada, contudo o que importa reter para um quadro geral da análise que me proponho é de alguma forma o contexto de certo desencanto com os rumos da revolução. Isto é inegável que influenciou não apenas a prática, mas também a teoria de Eisenstein, que impedido de filmar, passou a lecionar e a produzir farta reflexão teórica sobre o cinema, sobretudo no VGIK, o instituto de cinema russo que formava os novos quadros da indústria de cinema soviético.

Sokúrov, como veremos (CONDEE, 2009:162), não apenas estudou no VGIK, como foi agraciado como a bolsa de estudos Eisenstein para alunos de bom desempenho acadêmico e relata como não apenas até a sua formação as teorias e os filmes de Eisenstein são estudados, como relata o seu encanto particular com A Greve. Sokurov também participa de 
um notável momento de desencanto (ALBERA 2009), surgindo no período da estagnação brejneviana e de fato começando a produzir com mais vigor na era da Glasnost (BRASHINSKY, HORTON, 2008) - quando a Revolução Russa de alguma forma capitula.

Se descrevo estes fatos extracinematográficos aqui, não é para tirar o foco da reflexão da teoria de Eisenstein, mas para auxiliar na contextualização não apenas de um momento de desencanto e ruptura como estado, mas também para acentuar a visível presença formativa do pensamento de Eisenstein em Sokúrov, a partir de sua aprendizagem formal.

Do mesmo modo, como nenhum crítico deixou de notar (MACHADO, 2002), Andrei Tárkóvski é uma reconhecida influência em Sokúrov e passo, portanto agora a analisar as concepções teóricas particulares de Tarkóvski sobre o cinema - quase sempre considerado uma contraposição absoluta às concepções de Eisenstein.

Andrei Tarkóvski, que pode ser caracterizado - de forma simplificada para efeitos desta análise - por sua adesão a planos de longa duração, deixou uma série de intervenções que, segundo Jacques Aumont (2008), apresentam uma concepção de cinema em que a ênfase recai menos na montagem como oposição, conflito, mas sim no cinema como fluxo contínuo, fluxo temporal, uma entonação de caráter mais revelatório sobre a representação do real. Em Tarkóvski a significação estaria menos no choque entre planos do que nos sentidos proporcionados por uma longa contemplação. Aumont, em seu livro sobre as teorias advindas dos cineastas, comenta sobre Tarkóvski que:

É conhecida sua abominação da montagem analítica de Eisenstein, mas ela se estende ao domínio da direção: nem o cineasta, nem os atores devem se encontrar em situação de superioridade com relação ao que se trata de dizer ou de representar. O filme não é algo que se domine e calcule; trata-se de criar ou recriar uma experiência, que deve ser vivida pela primeira vez durante a filmagem. (AUMONT, 2008:62-63)

Tarkóvski, ainda segundo Aumont (2008), será um cineasta que retomará a antiga tradição do ícone russo, com uma dupla leitura: de um lado o ícone é meramente representativo, referencial e de outro lado, é metafórico (que é sua parte "artística"), não podendo ser analisada aprioristicamente: daí os longos planos, a contemplação, a montagem apenas quando a imagem já está saturada e carregada de significação construída pelo transcorrer temporal. É, portanto uma imagem partilhada em que o espectador é espiritualizado como por contágio com a alma do artista (um contágio de tipo mimético, segundo Aumont). A própria linguagem de Tarkóvski em seu livro, de orientação poética, sugere esta visada do partilhar com o artista um mundo de imagens, recuperando inclusive a noção de sagrado e de aura: 
Ao se emocionar com uma obra prima, uma pessoa começa a ouvir em si aquele mesmo chamado da verdade que levou o artista a criá-la. Quando se estabelece uma ligação entre a obra e seu espectador, este vivencia uma comoção espiritual sublime e purificadora. Dentro dessa aura que liga as obras primas e o público, os melhores aspectos das nossas almas se dão a conhecer e ansiamos por sua liberação. (TARKÓVSKI, 1998:49)

Seu próprio livro sobre seu pensamento cinematográfico, Esculpir o Tempo (TÁRKÓVSKI, 1998) deixa bastante evidente sua oposição declarada às concepções de Eisenstein, e sua defesa da arte do cinema como forma de talhar, esculpir, dar forma ao registro do tempo. Segundo o realizador o cinema seria uma arte propriamente do transcorrer temporal (TARKÓVSKI, 1998:64-94).

Nota-se em Tarkóvski, portanto, mais uma visada de caráter existencialista e de durée bergsoniana do que de vinculação ao marxismo dialético, ou mesmo de estranhamento como operação formal - o que não significa claro, que seus filmes sejam realistas ou naturalistas e que não provoquem desconforto. O que em Tarkóvski causa estranhamento e desconforto é justamente a ambiguidade do registro, onde o sentido de cada plano não é óbvio, e não segue uma prévia determinação dos efeitos que se deseja produzir.

Dessa forma, a montagem nunca entra em Tarkóvski como um instrumento particular de análise entre planos - como a essência do cinema e da própria arte como fendido por Eisenstein - mas sim de articulação temporal entre imagens de forte adesão emocional ao espectador. O plano, como diz Tarkóvski (1998), é como se fosse tempo impresso, e o cinema seria o esculpir o tempo, criar um ritmo temporal - porém não um tempo métrico, tonal ou atonal como em Eisenstein, mas um tempo abstrato, a experiência de vivenciar o tempo.

Como diz Tarkóvski: “Acho que a motivação principal de uma pessoa que vai ao cinema é uma busca do tempo" (TARKÓVSKI: 1998:72). Disto, segundo Aumont (2008), a noção negativa mesmo de Tarkóvski sobre a montagem, já que o ritmo deve ser construído não pela montagem, mas pela intensidade da experiência temporal dos planos, onde a montagem é uma virtualidade potencial da filmagem.

Agora é chegado o momento de se inquirir: E Sokúrov? Com que tipo de concepção (Eisenstein, Tarkóvski) seu cinema encontra mais proximidade? E, mais do que isso, de que forma, como penso, sua montagem e seu cinema de alguma forma, sintetizam essas duas concepções?

Sokúrov é comumente percebido como um herdeiro de Tarkóvski (ALBERA, 2009, CONDEE, 2009, MACHADO, 2002, DIETSCH, 2005). Embora o realizador negue 
categoricamente tal filiação e diversos críticos tenham apontado as diferenças entre os dois realizadores, há fatos extracinematográficos e questões estéticas que suportam essa visão.

Primeiro há o uma proximidade e um reconhecimento de Tarkovski ao talento de Sokúrov (TARKÓVSKI, 1998). Tarkóvski, por exemplo, empregará esforços para liberar a primeira obra de Sokúrov da censura do então estado soviético (trata-se do longa de ficção $A$ Voz solitária do Homem, 1977,1987); Sokurov, por sua vez, fará Elegia Moscovita (1990) sobre o exílio de Tarkóvski em uma espécie de diálogo com o cineasta. Mas, sobretudo há proximidades estéticas, como a prática comum de Sokurov de planos de longuíssima duração - cujo epítome é mesmo o filme de um único plano sequência de 97 min, Arca Russa (2002). É comum associar-se Sokúrov como mais próximo a um pensamento e prática do filme mais como transcorrer, cinema como fluxo, do que cinema como construção de blocos de significado, na linha de oposição, como o construtivismo russo e Eisenstein procuraram realizar e teorizar.

Dadas estas configurações, e acreditando ter demonstrado como a obra dos dois cineastas de alguma forma marca Sokúrov, gostaria de sugerir que o cinema deste realizador opera não segundo um ou outro princípio, mas de alguma forma, os reconfigura, enfatizando não apenas a ideia de fluxo temporal, mas igualmente a montagem no sentido mais einsensteniano do termo; a montagem como operação intelectual abstrata em planos que só fazem sentido no choque, na oposição. O filme Hubert Robert, que passo a analisar, pode ser uma boa ilustração dessa característica do diretor.

\section{O filme: Hubert Robert, uma vida afortunada e a concepção de Sokurov da montagem}

O filme Hubert Robert, uma vida afortunada (1996) é um documentário sobre o pintor francês do século XVIII, Hubert Robert. O pintor, também conhecido por Hubert das Ruínas, por sua obra ser caracterizada pela pintura de grandes paisagens com ruínas de palácios imaginários, filia-se a uma linhagem cujos autores mais conhecidos - com os quais, aliás, ele estudou em Roma - foram Panini, Servandoni e especialmente Piranesi (RADISICH, 1998). O principal acervo de Hubert Robert no mundo está no Hermitage em São Petersburgo, e o filme de Sokúrov, segundo Mikhail Iampolski (IAMPOLSKI, 1999:127) faz parte de uma série de filmes do diretor nunca completados sobre o museu Hermitage. Passo agora a sua descrição.

Na primeira sequência, logo na abertura do filme, temos o quadro aberto para uma paisagem brumosa. Em plano geral noturno, vemos figuras de uma multidão assistindo a uma 
representação de uma peça do Teatro Nô japonês. Um narrador off (o próprio Sokúrov) pergunta-se onde ele está, o que faz ali, quem são aquelas figuras, que parecem encantadas com aquela peça. A sequência prossegue com o narrador off, que diz não saber onde está, observando a maravilhosa peça Nô e comentando que não tem dúvida que ali estão grandes atores, por trás daquelas máscaras, e admirando o senso de beleza do espetáculo, o sentido respeitoso do público e lembrando-se de um texto de Dostoievski em que o escritor russo escreve que acordou em um lugar onde se sentia plenamente feliz, em que todos o compreendiam e o amavam. Seguem-se cenas da representação, sempre entre brumas noturnas, em um quadro levemente indistinguível, em que continua ocorrendo a ação da peça Nô.

Não sabemos em que época estamos, do que trata a peça Nô representada, o que está ocorrendo. Tudo o que sabemos é que ocorre uma peça, uma representação, e que figuras do teatro japonês representam com dedicação algum drama e que de alguma forma, o narrador off ali se sente bem. Planos lentos, longos, cortados em fusão, com a suave voz do diretor tecendo comentários sobre estética.

De início cabe a mais importante pergunta, uma pergunta de recepção: não era para vermos um documentário sobre um pintor francês de ruínas, do século XVIII, hóspede da corte peterburguense, e com obra considerável no Hermitage? O filme não está indexado como documentário sobre este pintor? O quê - pode se perguntar o espectador - aquelas imagens do teatro Nô estão fazendo ali? Por que o filme começa assim, quem é o narrador, onde estão os quadros de Robert?

Evidentemente este não pode ser um documentário tradicional sobre um pintor. Aqui a primeira operação de alto estranhamento. Não se fala de um pintor, não se mostram seus quadros, nem seus temas, então o que significam aquelas imagens e porque e como elas constroem um ensaio fílmico sobre o pintor Robert?

Então, na segunda sequência, dentro do espaço diegético dos arredores da encenação Nô, a câmera aproxima-se de uma árvore, e esta árvore, dissolve-se lentamente e transformase na árvore de uma pintura de Robert, no Hermitage. Vemos Robert, o pintor ele mesmo retratado, retratando-se no ato de compor uma pintura sobre uma ruína imaginária.

Isto é, Robert pinta o pintor Robert no ato de pintar uma cena de ruína imaginária e Sokúrov mostra este pintor dentro do quadro de Robert: a representação, dentro da representação, a mise en abîme, e agora, talvez, possa começar a fazer sentido a sequência do teatro Nô. Ou, melhor dizendo, assim como em Eisenstein, a operação de montagem de sequências tão díspares só pode adquirir significado pela oposição entre elas, pela operação 
propriamente intelectual e abstrata: o que não está em uma sequência nem em outra, mas na troca das duas; na, arrisco a dizer, teatralização da segunda, pelo efeito da primeira, isto é, na construção de um meta-tema que é a arquiteturalização do próprio quadro. O próprio quadro do pintor como ruína sobre ruínas, representação que se esfacela, traço brumoso e evanescente como as figuras Nô fantasmáticas. Assume-se assim um sentido de comentário mais profundo sobre o universo documentado do pintor - as ruínas como sentido da reflexão do artista, que Sokúrov retrata.

Só então, e a partir daí, podemos observar o mundo de Robert como mundo ficcional, enclausurado por uma arquitetura de ruínas, porque Sokúrov entra primeiro no espaço do museu a partir de sua teatralização, a partir do museu como espaço encantado, ele mesmo de ruínas, ele mesmo representação estilizada.

Ora, nada pode ser mais próximo da montagem de Eisenstein que esta operação criada exclusivamente pela montagem. Uma vez introduzido o tema do documentário, a voz off começa a narrar, a princípio titubeante, fatos sobre a vida do pintor Robert: sua data de nascimento, sua vida feliz por ser um caso raro, segundo o narrador, de alguém que se realiza plenamente com o que faz e é reconhecido e pago por isso.

As sequências então, oscilam entre o espaço cênico das pinturas, filmadas dentro do Hermitage, sempre em planos contemplativos, e com cortes - só que bruscos agora - e não em fusão, para as cenas do teatro Nô. Por exemplo, quando o narrador apresenta que nesta vida feliz do pintor, houve momentos de tristeza - o corte é brusco para o espaço cênico do teatro Nô. Na cena, um dos atores Nô faz um movimento repentino de 180 graus, sublinhado pela flauta com um sopro seco e agudo, sugerindo exatamente isso: um corte, um rompimento, uma guinada.

Ora, a partir de então, torna-se natural que o espaço cênico oriental do teatro Nô seja reconhecido como uma montagem em contraponto, como um comentário esclarecedor e igualmente misterioso sobre esta "vida feliz". Afinal, ironicamente, embora o subtítulo do filme seja esse, "uma vida feliz", todo o tom do documentário é elegíaco, e então fica-se conhecendo pela narração que não apenas o pintor se exilou na corte russa, quando da Revolução Francesa (e penso eu, que a escolha deste pintor parte de uma identificação pessoal do diretor e de um paralelismo com momento histórico sobre a situação Russa), mas todos os seus filhos morreram e ele morreu sozinho na Rússia.

É conhecida a apreciação de Eisenstein ao teatro Nô e esta relação de proximidade de Sokúrov a algumas ideias de Eisenstein como o de uma natureza não indiferente (COUREAU, 2009: 128,129). Do mesmo modo, como é conhecida a própria relação de Tarkóvski com a 
arte japonesa e não parece meramente casual que esta referência esteja colocada no filme Hubert Robert. Isto é, não apenas neste filme vemos como que uma nova síntese, entre estas duas vertentes artísticas do cinema russo, mas, além disso, observamos uma reconfiguração. A montagem intelectual continua a ocorrer, porém agora sem choque, sem surpresa, mantendo o estranhamento. O tempo longo, a duração interminável, porém sem adesão a um real, mas sim a uma representação do real, a uma teatralização do espaço fílmico, a um duplo representado pela metalinguagem do filme e pelos empréstimos híbridos às outras artes como o cinema, a literatura, a pintura, o teatro, a arquitetura.

A diferença, contudo, de Eisenstein, - talvez, significativa no caso de Sokúrov -, é que a montagem desse comentário em contraponto não procede segundo uma explicitação didática e unívoca, isto é, os sentidos abstratos e intelectuais criados pela montagem não conseguem ser imediatamente percebidos pelo espectador, vitimado por estranhamento e, sobretudo, no que se aproxima de Tarkóvski, pelo uso de tempos lentos, de fusões, de sobreimpressões, reduzindo, portanto o efeito de choque provocado pelo corte.

É como se em Sokúrov, neste filme analisado, o corte fosse suavizado por uma linha de fundo que costurasse as sequências, que sugerisse uma continuidade - ainda que uma continuidade paradoxal, uma continuidade sem espaço e tempo consequentes e sem uma dimensão lógico-temporal evidente. Eu sugeriria, portanto que a continuidade, dentro da montagem em Sokúrov, opera segundo a estratégia de estabelecer um fluxo temporal de permanência, bem no sentido de duração como em Tarkóvski, porém estabelece-se não na diegese fílmica, mas numa espécie de imagem mental surgida da oposição entre esses dois lugares.

E o que costura essa narrativa, naturalizando, se assim se pode colocar, esse estranhamento, e permitindo que as imagens sejam montadas indistintamente entre dois polos (O teatro Nô, o Hermitage) é a voz de Sokúrov, que em monólogo tipicamente interior, como que vai revelando e ao mesmo tempo apreendendo sobre a vida de Robert.

Isto é, não se trata também aqui de um narrador off seguro do que mostra: Sokúrov titubeia, vacila e sussurra, como se ouvisse uma voz de sua consciência. Para efeitos comparativos, este narrador é muito similar ao famoso narrador off (feito igualmente pelo diretor) do filme Arca Russa (2002), em que também ocorre um passeio, desta vez em um único plano, através de obras do Hermitage. O narrador em Arca Russa viaja pelo museu, comentando, tergiversando, sussurrando, procurando entender e descobrir o que vê, fazendo associações, paralelismos, descobertas, também sob um fundo trágico, no caso, uma espécie de baile fiscal russo. 
Esta narração off em Sokúrov, que conduz toda a narrativa, também poderá ser encontrada em numerosos outros filmes do diretor, sobretudo de não ficção, como por exemplo, a Trilogia Oriental (Elegia Oriental-1996; Uma Vida Humilde, 1997; Dolce, 1999), além de Vozes Espirituais (1995), Elegia de Uma Viagem (2001), entre outros.

É tentador nesse momento fazer ainda outra aproximação de Sokúrov com Eisenstein: o monólogo interior.

Como se sabe, com o nascimento do som, o encontro de Eisenstein com Joyce em Paris, seus roteiros e a versão para Uma Tragédia Americana, a partir do romance de Dreiser, e, sobretudo o vasto entusiasmo teórico de Eisenstein pela descoberta das potencialidades do som para os procedimentos de monólogo interior fizeram com que este realizador soviético chegasse mesmo ao arroubo de escrever que "o verdadeiro material do cinema sonoro é, evidentemente, o monólogo" (EISENSTEIN, A forma do filme, 2002: 105).

Ora, não parece, contudo, examinando melhor, que o monólogo interior, tal qual preconizado por Eisenstein seja o mesmo tipo de monólogo praticado por Sokúrov: não se trata do livre fluxo de consciência joyceano, em que a frase parece se interromper, e o texto sugere o ritmo do pensamento, como no paradigmático monólogo final de Molly Bloom (Ulisses, 1922). Mas, sem dúvida, o narrador sokuroviano, assim como na ideia de monologo interior, vai descobrindo o que ver, o que compreender, em uma narração estruturada, porém fragmentada, em crise, se posso assim definir.

Creio que o que melhor se aproxima do narrador off de Sokúrov é o empréstimo criativo ao conjunto de teorias sobre a poética do cinema, desenvolvidas pelos formalistas russos (ALBERA, 1998).

Boris Eikhenbaum (apud: ALBERA: 1998:201) irá propor no contexto do formalismo russo - ideias conhecidas por Eisenstein - a noção de um discurso interior do espectador- em que o espectador vai construindo o sentido do encadeamento sucessivo da montagem das "cine-frases" - termo utilizado por Eikhenbam e que não se reduz nem ao plano, nem às sequências, mas sim às unidades mínimas de sentido.

Este discurso interior do espectador, segundo Albera, é uma hipótese muito interessante "nunca assinalada e desenvolvida corretamente" (ALBERA, 1998:35), por se situar entre o discurso egocêntrico e o discurso socializado (nos termos de Vygotsky). Esse discurso interior seria mais imaginativo, cambiante e sincrético que o discurso exterior submetido às convenções da linguagem em geral. Parece sim, nesse caso, ajunto eu, que estamos agora falando do narrador vacilante e imaginativo de Sokúrov. 
Evidentemente, a investigação dessa hipótese ultrapassa longamente o escopo desse artigo, que procura apenas salientar e levantar uma teoria do formalismo russo e o cinema, que pode como que estabelecer uma ponte de síntese entre as teorias "duras" de Eisenstein e as teorias "fluidas" de Tarkóvski.

O filme Hubert Robert pode ser uma boa introdução a esse estilo de filmar e conceber a montagem em Sokúrov. Penso que reside aí a originalidade desta obra, que, por ser curta, como que condensa alguns dos traços estilísticos de Sokúrov, neste diálogo ambivalente e contraditório entre duas grandes correntes de pensamento e estética do cinema russo.

Se Sokúrov não é a síntese programática dessas duas vertentes do cinema russo - e seria muito reducionismo pensá-lo assim - contudo, creio que se torna bastante evidente como este realizador tem tomado empréstimos criativos desses dois autores essenciais do cinema russo, gerando talvez uma originalidade que, passo a nomear agora, por falta de melhor palavra, como uma originalidade sincrética e sintética - sobretudo nos procedimentos de montagem e narração, como penso haver aqui discutido.

\section{Referências Bibliográficas:}

ALBERA, François; ESTÈVE, Michel. Alexandre Sokourov. Paris, Editions Charles Corlet, 2009.

. Eisenstein e o Construtivismo Russo. São Paulo, Cosac Naify, 2002.

. (org). Los Formalistas Russos e el cine. Barcelona, paidós, 1998.

AUMONT, Jaques. As teorias dos cineastas. São Paulo, Papyrus, 2008.

BEUMERS, Birgit. A history of Russian cinema. New York, Berg, 2009.

Russia on Reels: the Russian idea in post-soviet cinema. New York, Ed. I.B. Tauris, 1999.

BRAHINSKY, Michael; HORTON, Andrew. Russian critics on the cinema of Glasnost. Cambridge, Cambridge Univ. Press, 2008.

CONDEE, Nancy. The Imperial Trace: recent Russian cinema. Oxford, Oxford Press, 2009.

COUREAU, Didier. Elégie de la Traversée: les voix spirituelles du temps. In: ALBERA, François; ESTÈVE, Michel. Alexandre Sokourov. Paris, Editions Charles Corlet, 2009.

DIETSCH, Bruno. Alexandre Sokourov. Lausanne, L'age d'homme, 2005.

EISENSTEIN, Serguei. A Forma do filme. Rio de Janeiro, Zahar, 2002. 
O sentido do filme. Rio de Janeiro, Zahar, 2002.

La non -indifférente nature/2. Paris, Union Générale dÉditions, 1978.

IAMPOLSKI, M. "Representation, Mimicry, Death: the latest films of Alexandr Sokúron" In: Russia on Reels: the Russian idea in post-soviet cinema. New York, Ed. I.B. Tauris, 1999, pgs $128,149$.

MACHADO, Alvaro (org). Aleksandr Sokúrov. São Paulo, Cosac \& Naify, 2002.

SOKÚROV, Aleksandr. Entrevista com Jeremi Szaniawski, Critical Inquiry, Vol 33, fall 2006.

The history of an artist's soul is a very sad history: interview with Alekasandr Sokurov, by Paul Schrader, Film Comment, Vol 33 \#6 Nov -1997.

RADISICH, Paula Rea. Hubert Robert: Painted Spaces of Enlightment. Cambridge, Cambridge Univ Press, 1998.

SCHAMA, Simon. O Poder da Arte. São Paulo, Cia das Letras, 2010.

SHKLOVSKY, Victor. Eisenstein. Barcelona, Anagrama, 1973.

TARKÓVSKI, Andrei. Esculpir o tempo. São Paulo, Martins Fontes, 1998.

XAVIER, Ismail. A experiência do Cinema. São Paulo, Graal, 2008. 